\title{
Effectiveness of lifestyle measures in the treatment of gastroesophageal reflux disease - a case series
}

\author{
Madeleine Nowak' \\ Petra Büttnerl \\ Simone Harrison' \\ Kym Daniell ${ }^{2}$ \\ Beverly Raasch ${ }^{2}$ \\ Rick Speare' \\ 'School of Public Health, Tropical \\ Medicine and Rehabilitation Sciences, \\ and ${ }^{2} \mathrm{School}$ of Medicine, North \\ Queensland Centre for Cancer \\ Research within the Australian \\ Institute of Tropical Medicine, James \\ Cook University, Townsville, Australia
}

\begin{abstract}
Aim: To assess the effectiveness of lifestyle measures in the treatment of gastroesophageal reflux disease (GERD) among adults attending a dietetic practice.

Methods: A retrospective case series of adult patients presenting with GERD to a dietetic practice over a three year period. The routine lifestyle counselling for treatment of symptoms of GERD included: not reclining within two to three hours of eating; a diet low in fat; small frequent meals; avoiding dietary components considered to relax the lower esophageal sphincter; and avoiding local irritants.

Results: Twenty three cases were included (12 male). Eighteen, (9 female) were referred by their doctor, 7 (6 female) presented for GERD alone, 7 (4 female) presented for GERD together with comorbidities, and 9 (1 female) incidentally mentioned GERD during a dietary consultation for another disorder. Thirteen participants ( 9 female) had previously undergone endoscopies, 18 (11 female) were taking medication for GERD, and 19 (7 female) had comorbidities. Twenty two (10 female) reported an improvement in symptoms with 11/18 taking GERD medication at presentation reducing their medication following treatment.

Conclusions: These results suggest that a more thorough investigation of lifestyle modification in the treatment of GERD is warranted.

Keywords: lifestyle modification, gastroesophageal reflux disease, symptom reduction, diet, case series
\end{abstract}

\section{Introduction}

Gastroesophageal reflux disease (GERD) is a common disorder with the classical symptoms being heartburn and regurgitation, and the less common symptoms including dysphagia, laryngitis, asthma and chest pain (Isselbacher et al 1994). Early data (1976) from the US suggested that 7\% of the adult population experienced symptoms daily and around 36\% had these symptoms at least once a month (Nebel et al 1976). These data are likely to be the source of the commonly quoted figure of almost $40 \%$ of adults experiencing these symptoms. However, a more recent study found that $22 \%$ of American adults reported daily symptoms of heartburn and 57\% reported such symptoms at least weekly (Oliveria et al 1999). Due to the differences in study methodology, it remains unclear whether or not these two studies actually demonstrate an increase in incidence of GERD over the 20 year interval. In Australia, results of a telephone survey in New South Wales seeking information about symptoms of dyspepsia in the previous three months reported a prevalence of $11.4 \%$ to $36 \%$ depending on the definition used (Westbrook and Talley 2002). Another Australiawide telephone survey found that $37 \%$ of respondents reported experiencing heartburn at least once every 4-6 months (Bolin et al 2000).

While the symptoms of GERD are painful and debilitating for the patient, reflux is a serious disorder because it is associated with the development of Barrett's esophagus and adenocarcinoma of the esophagus and gastric cardia (Cohen and 
Parkman 1999). The aetiology of Barrett's esophagus, a metaplastic process in which native squamous epithelium of the distal esophagus is replaced by columnar epithelium, is unknown, however, clinical and experimental data implicate GERD (Oberg et al 1998). There is evidence for a “probably causal” relationship between GERD and adenocarcinoma of the esophagus, with less clear evidence of a link between reflux and adenocarcinoma of the gastric cardia (Lagergren et al 1999).

The incidence of these two cancers (adenocarcinoma of the esophagus and gastric cardia) is rising faster than that of any other cancer in the US (DeMeester and DeMeester 1999). In addition, an 8-fold increase in esophageal adenocarcinoma has been reported in Denmark between 1970 and 1990. This increase was not explained by changes in classification or diagnosis (Bytzer et al 1999). The incidence of this cancer is also rising in Australia (Lord et al 1998). The reason for the increasing incidence of these cancers is unclear (Falk and Richter 1998). However, the likely increase in the prevalence of GERD, the increase in obesity (Mayne and Navarro 2002), and the decline in Helicobacter pylori colonisation (associated with lower birth rates and the use of antibiotics, together with a change in the number and type of variants of the bacterium; Blaser 1999) have been suggested as possible causes.

The mechanisms resulting in GERD are complex and affected by many factors including the anatomy, genetics and environment of the individual (Vandenplas and Hassall 2002). Many studies have investigated the effects of individual dietary components on normal volunteers and people with GERD (Grande et al 1997; Holloway et al 1997; Pehl et al 1999, 2001; Meyer et al 2001; Colombo et al 2002). However the results of such studies remain contradictory.

A review of the earlier literature concluded that lifestyle modifications have been shown to be effective in the treatment of GERD (Kitchin and Castel 1991), however, there have been few well-designed placebo-controlled trials. Subsequently it has been suggested that many of these lifestyle changes would not be of benefit in alleviating the symptoms of GERD, although they would be appropriate for promoting general health (Galmiche et al 1998). A more recent review has identified lifestyle recommendations which are likely to be effective and those with little supporting evidence (Meining and Classen 2000).

Considerable debate remains about the type of treatment that should be recommended for the disease, with these discussions focusing mostly on medication and surgery
(Katz 2002) with little mention of lifestyle modification. Although conservative therapy (diet, posture, antacids), was the only treatment for GERD until the advent of the antisecretory drugs, the current usage and associated success rate is unknown. Lifestyle treatment of GERD, in addition to medication, is recommended in both Australia (Katelaris et al 2002) and US (DeVault and Castell 1999) and its use has been documented in studies of general practitioners in Germany (Meining et al 2002) and Australia (Nowak et al 2005). Such advice has been provided "despite the lack of scientific evidence” (Meining et al 2002). Furthermore, participants in a US study investigating the perceived effects of dietary intake on symptoms of 'heartburn' among 2000 individuals identified a number of foods which they believed precipitated their GERD symptoms (Oliveria et al 1999).

Our clinical experience has implicated similar dietary factors and suggested that lifestyle modification may reduce both the symptoms of GERD and patient reliance on medication to treat this disorder. We retrospectively evaluated the outcome of this treatment among patients attending a dietetic practice over a three-year period.

\section{Methods and materials Participants}

All records of adult patients presenting to one private dietetic practice in Townsville (approximately 130000 inhabitants), Australia, between 1 July 1999 and 30 June 2002 were examined retrospectively in August 2002. Patients who presented either specifically for the treatment of GERD symptoms, or who complained of GERD symptoms during a consultation for another disorder were considered for this case series. However, only those patients who had attended an initial dietetic consultation and at least one review were included in the case series $(n=24)$. One patient, who was initially included, was subsequently found to have been prescribed a proton pump inhibitor between the two dietetic consultations and was therefore excluded.

\section{Intervention}

In this practice, all patients who mention heartburn, reflux, indigestion, or esophagitis are routinely given standardized dietary and postural advice to alleviate GERD symptoms as a first line of treatment. This advice includes: not reclining within two to three hours of eating; a diet low in fat; small frequent meals; avoiding dietary components considered to relax the lower esophageal sphincter; and avoiding local irritants (eg, citrus juices, tomato concentrates, and spices) 
(Zeman 1983). It is suggested that these modifications be adhered to rigorously for one month, followed by a careful trial of individual components to identify those that should be excluded in future.

\section{Data collection}

Data collected from standard patient records included, sex, age, height, weight, medication, number of consultations, time between the first and the last consultation, use of alcohol and tobacco, exercise level, dietary intake, GERD symptoms, and comorbidities. As patients had routinely been asked open ended questions about their reflux symptoms, their subjective responses were also collected from the patient records. Patients were not systematically questioned about prior endoscopies, but for the purposes of this case series were considered to not have undergone an endoscopy if it was not mentioned either by the referring doctor or by the patient during the consultation. Patients were asked to self-report the frequency and severity of GERD symptoms and the use of GERD medication.

\section{Statistical analysis}

Data were analysed using SPSS for Windows, release 6.3. Numerical data were described using mean and standard deviation (SD) or median and interquartile range, as appropriate. Valid percentages (ie, percentages calculated by excluding patients with missing information) were given for categorical variables. Comparisons between gender were conducted using Chi-square tests (asymptotic and exact), Fisher's exact test, t-tests, and non-parametric Wilcoxon tests, as appropriate. Frequency (none, occasional, less than daily, daily) and severity (none, mild, moderate, severe) of symptoms were assessed at initial presentation and after treatment and were tested for significant changes using exact paired McNemar tests. Changes in weight and body mass index were assessed using paired non-parametric Wilcoxon tests.

\section{Results}

A total of 23 patients (12 males) were included in the present case series. The mean age of these patients was 50.2 years ( $\mathrm{SD} \pm 12.6$ years) with the age distribution being five between 20 and 39 years ( 4 female), 14 between 40 and 59 years ( 4 female), and four were at least 60 years old ( 3 female). The majority of patients had been referred to the dietetic clinic by a general practitioner $(n=18)$, had previously had an endoscopy ( $n=13)$, had comorbidities at presentation $(n=19)$, and were taking medication to relieve GERD symptoms at presentation $(\mathrm{n}=18)$ (Table 1). Females were more likely than males to present specifically for the treatment of GERD symptoms ( $p=0.003)$, and to have had an endoscopy $(\mathrm{p}=0.019)$ (Table 1). The median alcohol intake was 0.5 standard drinks per day with interquartile range (IQR) 0.05 2.1 and range $0-20$.

More males than females presented with comorbidities $(p=0.037)$, with the most common comorbidities being obesity, hyperlipidemia, and hypertension (Table 2). The majority of the patients were taking prescribed medication for GERD ( $\mathrm{n}=15$ ) with an additional three taking over the counter medication for this disease (21 patients with valid information) (Table 2).

At initial presentation, 13 of 21 patients with valid information reported daily symptoms of GERD with eight reporting less frequent symptoms. Of those 21 patients, 18 classified their symptoms as severe and three as moderate.

All but one patient reported a decrease in frequency and/ or severity of symptoms following treatment. This exception was a 79 year old female with a body mass index of $17.2 \mathrm{~kg} /$ $\mathrm{m}^{2}$, who presented specifically because of GERD which had been confirmed at endoscopy. She was taking a proton pump inhibitor (twice daily) to treat the following symptoms, which she had had for more than 30 years: nausea; reflux cough; hoarse voice; regular burping, and flatulence; and occasional central upper abdominal pain. After a rigorous trial of the "reflux" diet she reported no change in either symptoms or the use of medication.

Of the remaining 22 patients, eight (3 female) were completely symptom free following treatment; eight (5 female) reported only having symptoms of GERD when they "broke the lifestyle rules"; and five (1 female) reported a reduction in the frequency and/or severity of their GERD symptoms following treatment. The specific symptoms of one patient were not recorded, although she reported marked improvement at her review appointment. Overall, frequency $(p<0.001)$ and severity $(p=0.002)$ of symptoms improved after treatment.

Of the 18 patients for whom weight data were available at initial and final presentation, 12 had lost weight, 3 had gained weight, and 3 had remained the same weight, with the range of weight change being -8 kilograms to +2 kilograms (Table 1 ). Weight $(\mathrm{p}=0.007$ ) was significantly reduced after treatment. There were no significant differences in overall improvement $(\mathrm{p}=0.3330)$ or frequency of symptoms ( $\mathrm{p}=0.5908)$ between patients who had lost weight during the treatment period and those who had not. 
Table I Characteristics of 23 adult patients with gastroesophageal reflux disease (GERD) attending a dietetic practice in Townsville, Australia

\begin{tabular}{|c|c|c|c|c|}
\hline & $\begin{array}{l}\text { Total } \\
(n=23)\end{array}$ & $\begin{array}{l}\text { Male } \\
(n=\mid 2)\end{array}$ & $\begin{array}{l}\text { Female } \\
(n=I I)\end{array}$ & p-value ${ }^{a}$ \\
\hline \multicolumn{5}{|l|}{ Baseline characteristics } \\
\hline Mean age $\left( \pm S D^{b}\right)$ in years & $50.2(12.6)$ & $50.8(6.1)$ & $49.5(17.5)$ & $p=0.832$ \\
\hline Referred by general practitioner & $18(78.2 \%)$ & $9(75.0 \%)$ & $9^{d}(81.8 \%)$ & $\mathrm{p}=\mathrm{I}^{\mathrm{e}}$ \\
\hline \multicolumn{5}{|l|}{ Presented for: } \\
\hline GERD alone & 7 (30.4\%) & I (8.3\%) & $6(54.5 \%)$ & \\
\hline GERD plus other disease & 7 (30.4\%) & $3(25.0 \%)$ & $4(36.4 \%)$ & \\
\hline Incidentally mentioned GERD & $9(39.1 \%)$ & $8(66.7 \%)$ & $\mathrm{I}(9.1 \%)$ & $\mathrm{p}=0.003^{\mathrm{e}}$ \\
\hline History of endoscopy & $13(56.5 \%)$ & $4(33.3 \%)$ & $9(81.8 \%)$ & $p=0.019$ \\
\hline Using GERD medication at presentation & $18(85.7 \%)$ & 7 (70.0\%) & II (100\%) & $\mathrm{P}=0.090^{\mathrm{e}}$ \\
\hline Comorbidities at presentation & $19(82.6 \%)$ & $12(100 \%)$ & $7(63.6 \%)$ & $\mathrm{p}=0.037^{\mathrm{e}}$ \\
\hline \multicolumn{5}{|l|}{ Number of patients consuming } \\
\hline$>$ I standard alcoholic drink/day (I missing) & $6(27.3 \%)$ & $4(33.3 \%)$ & $2(20.0 \%)$ & $p=0.646^{e}$ \\
\hline Number of smokers (5 missing) & $2(11.1 \%)$ & I (I2.5\%) & I (I0.0\%) & $\mathrm{p}=\mathrm{I}^{\mathrm{e}}$ \\
\hline $\begin{array}{l}\text { Median body mass index at initial } \\
\text { presentation }\left(\mathrm{kg} / \mathrm{m}^{2}\right)[\mathrm{IQR}]^{\mathrm{c}}(5 \text { missing })\end{array}$ & $30.1[26.8,32.5]$ & $30.2[27.3,33.5]$ & $28.0[24.3,31.6]$ & $\mathrm{p}=0.20 \mathrm{I}^{\mathrm{e}}$ \\
\hline \multicolumn{5}{|l|}{ Treatment } \\
\hline Median number of visits [IQR] & $2[2,5]$ & $2[2,5.25]$ & $3[2,5]$ & $p=0.608^{e}$ \\
\hline Median period of visits [IQR] in months & $1.5[1.0,7.0]$ & $1.3[1.0,5.9]$ & $2[1.3,7.0]$ & $\mathrm{P}=0.347^{\mathrm{e}}$ \\
\hline \multicolumn{5}{|l|}{ Outcome } \\
\hline $\begin{array}{l}\text { Number of patients with reduction in } \\
\text { frequency of symptoms }\end{array}$ & 19 (90.5\%) & II (9I.7\%) & 8 (88.9\%) & $p=l^{e}$ \\
\hline $\begin{array}{l}\text { Number of patients with reduction in } \\
\text { severity of symptoms }\end{array}$ & $10(47.6 \%)$ & 7 (58.3\%) & $3(33.3 \%)$ & $\mathrm{P}=0.387^{\mathrm{e}}$ \\
\hline Decrease in medication (number and/or type $)^{f}$ & II (73.3\%) & $3(60.0 \%)$ & $8(80.0 \%)$ & $\mathrm{p}=0.560^{\mathrm{e}}$ \\
\hline Median weight change ${ }^{g}(\mathrm{~kg})[\mathrm{IQR}]$ & $-1.5[-3.6,0.0]$ & $-3.0[-5.5,-0.5]$ & $-1.0[-2.8,0.5]$ & $\mathrm{p}=0.165^{\mathrm{e}}$ \\
\hline
\end{tabular}

Notes: ${ }^{\mathrm{a}} \mathrm{p}$-value relates to comparison between the genders; ${ }^{\mathrm{b}} \mathrm{SD}$, standard deviation; ${ }^{\mathrm{C}} \mathrm{QR}$, inter-quartile range; ${ }^{\mathrm{d}}$ One patient presented following a suggestion from a GP (not her own GP) in a social situation; ${ }^{\mathrm{e}} \mathrm{p}$-value result of exact test; ${ }^{\mathrm{f}} \mathrm{Data}$ on medication was available for 15 patients at initial presentation and after treatment;

sWeight data available for 18 patients.

However, patients who had lost weight during the treatment period were more likely to experience less severe GERD symptoms than those who had not lost weight ( $\mathrm{p}=0.0365)$.

Eleven of the 18 patients who were taking GERD medication at presentation reported a reduction in the use of GERD medication, although there was no encouragement given during consultations for patients to reduce either the type or quantity of GERD medication.

\section{Discussion}

The results of this case series suggest that lifestyle modification may have at least an adjunct role to play in the treatment of GERD. All but one of the patients reported a reduction in GERD symptoms following a rigorous trial of lifestyle modification, with the majority reporting either no symptoms or only occasional symptoms for which they could identify the cause. In addition, more than half the patients who were using medication for the treatment of GERD had also reduced the type or frequency of medication.
The literature contains many reports of studies specifically examining the effects of weight loss, fat intake, and many of the local irritants incorporated into the advice given to these patients (Kitchin and Castell 1991). These studies have examined dietary components individually and have been conducted rigorously, but the results have not been consistent (Meining and Classen 2000). The patients reported here have been treated quite differently, with all components of lifestyle modification being tested for weeks rather than individual components being tested for hours. Furthermore, the endpoint in this work was patient symptoms whereas most studies have examined the effect on the lower esophageal sphincter or esophageal pH (Grande et al 1997; Holloway et al 1997; Pehl et al 1999, 2001; Colombo et al 2002). It is thus difficult to make any comparisons between the results obtained from these patients and the results of previously published studies.

Some reflux symptoms have been shown to be associated with obesity (Talley et al 2004) and weight loss is generally considered to reduce the symptoms of GERD (Kitchin and 
Table 2 Medication and comorbidities at initial presentation of 23 adult patients with gastroesophageal reflux disease (GERD) attending a dietetic practice in Townsville, Australia

\begin{tabular}{|c|c|c|c|}
\hline & Total $(n=23)$ & $\operatorname{Male}(n=12)$ & $\operatorname{Female}(n=I I)$ \\
\hline \multicolumn{4}{|l|}{ GERD medication $^{\mathrm{a}}$} \\
\hline Number of patients using GERD medication at presentation & $18(85.7 \%)$ & $7(70.0 \%)$ & II (I00\%) \\
\hline Number of patients using antacids & $2(9.5 \%)$ & $\mathrm{I}(10.0 \%)$ & I (9.1\%) \\
\hline Number of patients using alginates & I (4.8\%) & I (I0.0\%) & 0 \\
\hline Number of patients using $\mathrm{H} 2$-antagonists & II (52.4\%) & $4(40.0 \%)$ & 7 (63.6\%) \\
\hline Number of patients using proton pump inhibitors & $5(23.8 \%)$ & I (I0.0\%) & $4(36.4 \%)$ \\
\hline \multicolumn{4}{|l|}{ Comorbidities $^{\mathrm{b}}$} \\
\hline Number of overweight patients ${ }^{\mathrm{c}}\left(\mathrm{BMI}{ }^{\mathrm{d}} \geq 25\right.$ and $\left.\mathrm{BMI}<30\right)$ & $6(30.0 \%)$ & $2(18.2 \%)$ & $4(44.4 \%)$ \\
\hline Number of obese patients ${ }^{c}(B M I>30)$ & II (55.0\%) & $8(72.7 \%)$ & $3(33.3 \%)$ \\
\hline Number of patients with hypertension & $8(34.8 \%)$ & $5(41.7 \%)$ & $3(27.2 \%)$ \\
\hline Number of patients with hyperlipidemia & $12(52.2 \%)$ & $9(75.0 \%)$ & $3(27.2 \%)$ \\
\hline Number of patients with history of coronary artery bypass surgery & $2(8.7 \%)$ & $2(16.7 \%)$ & $0(0.0 \%)$ \\
\hline $\begin{array}{l}\text { Number of patients with non-insulin dependent diabetes mellitus or } \\
\text { impaired glucose tolerance }\end{array}$ & $4(17.4 \%)$ & $3(25.0 \%)$ & I (9.0\%) \\
\hline Number of patients with diverticulitis or "bowel problems" & $4(17.4 \%)$ & $3(25.0 \%)$ & I (9.0\%) \\
\hline Number of patients with chronic pain & $2(8.7 \%)$ & $2(16.7 \%)$ & $0(0.0 \%)$ \\
\hline Number of patients with post traumatic stress disorder & $3(13.0 \%)$ & $3(25.0 \%)$ & $0(0.0 \%)$ \\
\hline Number of patients with gout & I (4.3\%) & I (8.3\%) & $0(0.0 \%)$ \\
\hline Number of patients with asthma & I (4.3\%) & $0(0.0 \%)$ & I (9.0\%) \\
\hline Number of patients with osteoporosis & I (4.3\%) & $0(0.0 \%)$ & I (9.0\%) \\
\hline Number of patients with migraines & I (4.3\%) & I (8.3\%) & $0(0.0 \%)$ \\
\hline
\end{tabular}

Notes: a Some patients presented using more than one medication; information given is based on 21 patients; ${ }^{b}$ Some patients had multiple comorbidities; ${ }^{\mathrm{C}}$ Weight was unavailable for 3 patients; ${ }^{\mathrm{d}} \mathrm{BMI}$, body mass index $\left(\mathrm{kg} / \mathrm{m}^{2}\right)$.

Castell 1991; Meining and Classen 2000). Yet, among these patients, there did not appear to be any difference in the overall effect of treatment on symptoms between those who had lost weight, those who had gained weight, or remained the same. However, those who had lost weight did report a decrease in the severity, but not frequency, of symptoms. As there were only a small number of participants in this study, it is not possible to determine whether weight loss or the lifestyle changes leading to weight loss were responsible for the improvement in symptoms. For many of these patients reducing the symptoms of GERD was far more important than weight loss, thus weight loss occurred almost as a consequence of treatment for GERD. Thus careful questioning about symptoms of GERD by clinicians, and encouraging treatment of these symptoms by lifestyle modification may act as a motivator to change to more healthful dietary behavior.

This case series included a carefully selected group of patients, either selected by their doctors, or self selected. The grounds for selection were probably: being prepared to consider lifestyle modification for treatment of disease; placing a high priority on health therefore being prepared to attend a private dietetic practice; and preferring not to take medication if it could be avoided. Only those patients who returned for review were included. Hence, these patients may have been particularly motivated and thus not representative of the wider population suffering from GERD. It is certainly possible that a number of patients who derived no benefit from treatment chose not to return for review and thus this case series may represent a "best case scenario".

As the results are based on a small number of cases, they should be interpreted with caution. Nevertheless, this case series has shown encouraging results and indicates that a randomized controlled intervention to fully evaluate the efficacy of lifestyle modification in the treatment of symptoms of GERD is probably justified.

\section{Acknowledgements}

Funding for this work was provided by the Queensland Cancer Fund, the Parkes Bequest (James Cook University), and Queensland Health. Madeleine Nowak is supported by a Research Fellowship from the Queensland Cancer Fund, and Simone Harrison is supported by a Research Fellowship from Queensland Health.

\section{References}

Blaser MJ. 1999. Hypothesis: the changing relationships of Helicobacter pylori and humans: implications for health and disease. J Infect Dis, 179:1523-30.

Bolin TD, Korman MG, Hansky J, et al. 2000. Heartburn: community perceptions. J Gastroenterol Hepatol, 15:35-9. 
Bytzer P, Christensen PB, Damkier P, et al. 1999. Adenocarcinoma of the esophagus and Barrett's esophagus: a population-based study. Am J Gastrenterol, 94:86-91.

Cohen S, Parkman HP. 1999. Heartburn: a serious symptom. $N$ Eng $J$ Med, 340:878-9.

Colombo P, Mangano M, Bianchi PA, et al. 2002. Effect of calories and fat on postprandial gastro-oesophageal reflux. Scand J Gastroenterol, 37:3-5.

DeMeester SR, DeMeester TR. 1999. The diagnosis and management of Barrett's esophagus. Adv Surg, 33:29-68.

DeVault KR, Castell DO. 1999. Updated guidelines for the diagnosis and treatment of gastroesophageal reflux disease. The Practice Parameters Committee of the American College of Gastroenterology. Am J Gastroenterol, 94:1434-42.

Falk GW, Richter JE. 1998. Why is esophageal adenocarcinoma increasing in incidence? Abdom Imaging, 23:539-42.

Galmiche JP, Letessier E, Scarpignato C. 1998. Treatment of gastrooesophageal reflux disease in adults. BMJ, 316:1720-23.

Grande L, Manterola C, Ros E, et al. 1997. Effects of red wine on 24-hour esophageal $\mathrm{pH}$ and pressures in healthy volunteers. Dig Dis Sci, 42:1189-93.

Holloway RH, Lyrenas E, Ireland A, et al. 1997. The effect of intraduodenal fat on lower oesophageal sphincter function and gastro-oesophageal reflux. Gut, 40:449-53.

Isselbacher KJ, Braunwald E, Wilson JD, et al. (eds). 1994. Harrison's Principles of Internal Medicine, 13th ed. New York: McGraw-Hill Inc.

Katz PO. 2002. Gastroesophageal reflux disease: new treatments. Rev Gastroenterol Disord, 2:66-74.

Katelaris P, Holloway R, Talley N, et al; Digestive Health Foundation of the Gastroenterological Society of Australia. 2002. Gastrooesophageal reflux disease in adults: Guidelines for clinicians. $J$ Gastroenterol Hepatol, 17:825-33.

Kitchin LI, Castell DO. 1991. Rationale and efficacy of conservative therapy for gastroesophageal reflux disease. Arch Intern Med, 151:448-54.

Lagergren J, Bergstrom R, Lindgren A, et al. 1999. Symptomatic gastroesophageal reflux as a risk factor for esophageal adenocarcinoma. $N$ Eng J Med, 340:825-31.

Lord RV, Law MG, Ward RL, et al. 1998. Rising incidence of oesophageal adenocarcinoma in men in Australia. J Gastroenterol Hepatol, 13:35662.
Mayne ST, Navarro SA. 2002. Diet, obesity and reflux in the etiology of adenocarcinomas of the esophagus and gastric cardia in humans. $J$ Nutr, 132(11 Suppl):3467S-70S.

Meining A, Classen M. 2000. The role of diet and lifestyle measures in the pathogenesis and treatment of gastroesophageal reflux disease. Am J Gastroenterol, 95:2692-97.

Meining A, Driesnack U, Classen M, et al. 2002. Management of gastroesophageal reflux disease in primary care: results of a survey in 2 areas in Germany. Z Gastroenterol, 40:15-20.

Meyer JH, Lembo A, Elashoff JD, et al. 2001. Duodenal fat intensifies the perception of heartburn. Gut, 49:624-28.

Nebel OT, Fornes MF, Castell DO. 1976. Symptomatic gastroesophageal reflux: incidence and precipitating factors. Am J Dig Dis, 21:953-6

Nowak M, Büttner P, Raasch B, et al. 2005. Lifestyle changes as a treatment of gastroesophageal reflux disease - a survey of general practitioners in North Queensland, Australia. Ther Clin Risk Manage, 1:219-24.

Oberg S, Clark GW, Demeester TR. 1998. Barrett's esophagus. Update of pathophysiology and management. Hepatogastroenterol, 45:1348-56.

Oliveria SA, Christos PJ, Talley NJ, et al. 1999. Heartburn risk factors, knowledge, and prevention strategies: a population-based survey of individuals with heartburn. Arch Intern Med, 159:1592-98.

Pehl C, Pfeiffer A, Waizenhoefer A, et al. 2001. Effect of caloric density of a meal on lower oesophageal sphincter motility and gastrooesophageal reflux in healthy subjects. Aliment Pharmacol Ther, 15:233-9.

Pehl C, Waizenhoefer A, Wendl B, et al. 1999. Effect of low and high fat meals on lower esophageal sphincter motility and gastroesophageal reflux in healthy subjects. Am J Gastroenterol, 94:1192-6.

Talley NJ, Quan C, Jones MP, et al. 2004. Association of upper and lower gastrointestinal tract symptoms with body mass index in an Australian cohort. Neurogastroenterol Motil, 16:413-19.

Vandenplas Y, Hassall E. 2002. Mechanisms of gastroesophageal reflux and gastroesophageal reflux disease. J Pediatr Gastroenterol Nutr, 35:119-36.

Westbrook JI, Talley NJ. 2002. Empiric clustering of dyspepsia into symptom subgroups: a population-based study. Scand J Gastroenterol, 37:917-23.

Zeman FJ. 1983. Clinical nutrition and dietetics. New York: MacMillan. 